\section{It is Time to Celebrate Humanism} in Medicine!

Raghav Govindarajan, MD

\section{Department of Neurology, University of Missouri Health Care, Columbia, MO, USA 65201}

Last week, the school of medicine celebrated its second annual Gold Humanism Honor Society induction where 15 third year medical students who had displayed exemplary humanistic care throughout their clerkship were inducted into the honor society. The Gold Humanism Honor Society (GHHS) members are peer nominated and are the ones that others say they want taking care of their own family.

Unlike the traditional honor societies membership in GHHS signifies the students are specifically committed to the highest level of compassionate patient/family centered care and more importantly the creation of a GHHS chapter signifies that an institution places high value on the interpersonal skills and attitudes that are essential for the highest level of patient care'.

As the GHHS chapter advisor, I am thrilled to see humanistic patient centered care getting its due under the sun and being celebrated by the school of medicine. As I saw those 15 bright students recite the oath and don the pin, I was reminded of my own experience with doctors.

My aunt who was in her 30s had developed chest pain while teaching at the school. She was evaluated by the school nurse who thought the chest pain was due to acid reflux and gave her some antacids. The chest pain continued all night and got worse the next day. She was evaluated by her primary care physician who immediately recognized she was having a heart attack (myocardial infarction) and she was taken to the 'big hospital' in the town. We were all anxious and I distinctly remember my mother (her sister) crying. We were scared, confused and lost coming to the big hospital not knowing what to expect and whom to speak with.

My mother tried to talk with one of the doctors taking care of my aunt. He was in his mid-thirties moderately built with a husky voice. As my mother started talking to him, he seemed disinterested, had no eye contact, didn't refer to my aunt by her name and kept addressing her as 'case number' and even seemed annoyed that we were asking questions.

Our anxieties only got worse after this and although none of us had slept for more than day, we could not close our eyes. Then as the shift changed, a new doctor came in to take care of her. He was mild mannered but quickly built a rapport with us, held my mother's hand and spent more than an hour answering all our questions. Most importantly, he had a calm reassuring voice.

We were finally able to close our eyes and sleep. My aunt recovered from there on and was back to teaching in a month and continues teaching (it's been more than 15 years).

Medical schools have come a long way from days of labeling patients as cases. Providing patient centered, humanistic care has slowly but surely become a part of the medical school syllabus. Yet the stratosphere of physicians is occupied by physicians with large grants, physicians with administrative background, physicians with encyclopedic medical knowledge and so on. Research, diagnostic acumen and even administration are all very essential but there is enough space in the stratosphere to include those physicians who have been recognized as providing exemplary humanistic care by patients, medical staff and colleagues alike. These physicians should be honored and celebrated and made into role models for students to emulate. Both Sherlock Holmes and Dr. Watson need to be celebrated. For Dr. House fans, both Dr. House and Dr. Wilson need to be celebrated!

\section{Corresponding author:}

Raghav Govindarajan MD

Email: govindarajanr@health.missouri.edu 